Supplement of Atmos. Chem. Phys. Discuss., 15, 2157-2196, 2015

http://www.atmos-chem-phys-discuss.net/15/2157/2015/

doi:10.5194/acpd-15-2157-2015-supplement

(C) Author(s) 2015. CC Attribution 3.0 License.

(c) (1)

\title{
Temporal and spatial scaling impacts on extreme precipitation
}

\section{B. Eggert et al.}

Correspondence to: B. Eggert (bastian.eggert@hzg.de) 

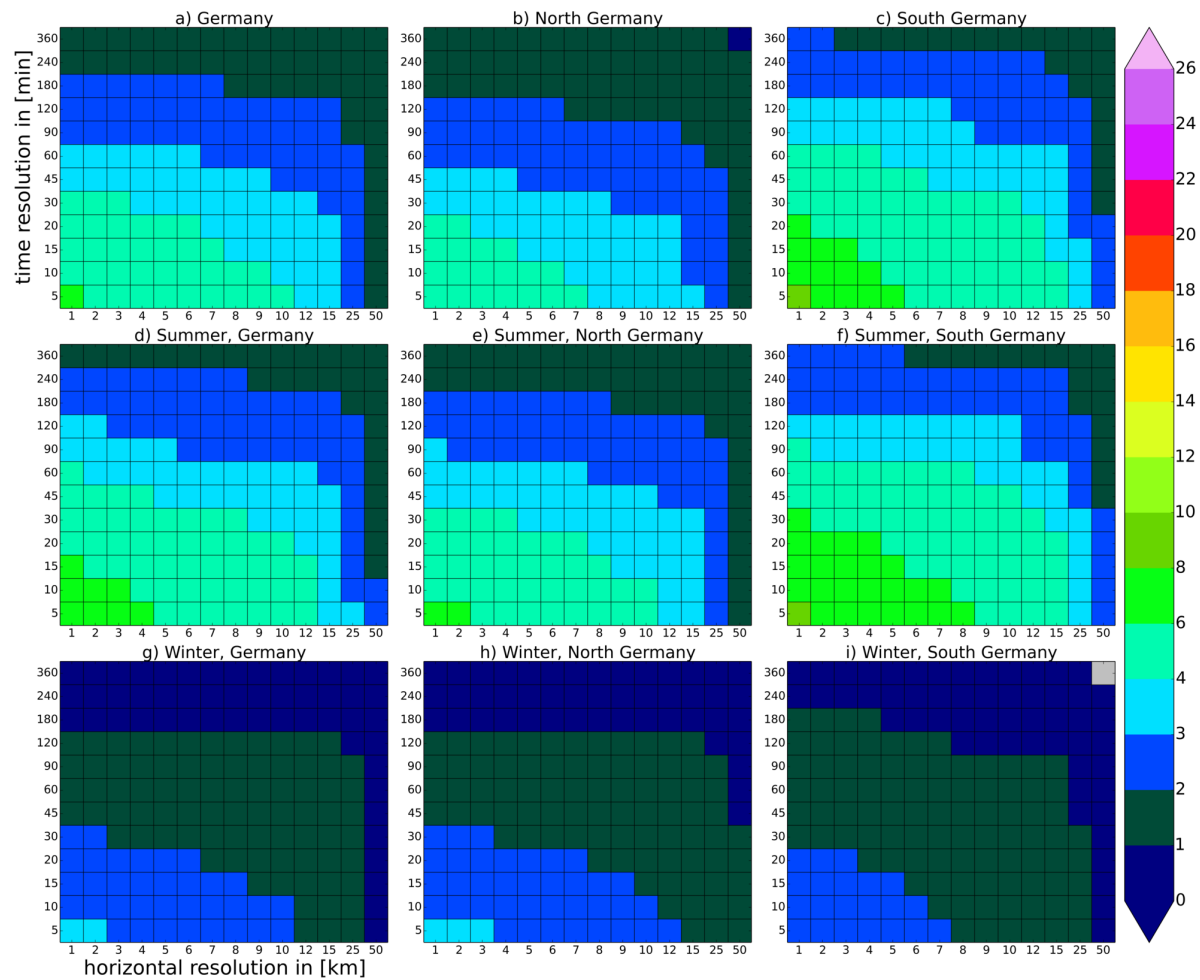

Figure 1: Convective extremes as function of resolution. The 95th percentile of convective precipitation intensities, aggregated over different parts of Germany for the years 2007-2008, on different horizontal (horizontal axis) and temporal (vertical axis) resolutions: Entire year (a,b,c), summer season (d,e,f) and winter season $(\mathrm{g}, \mathrm{h}, \mathrm{i})$. All of Germany $(\mathrm{a}, \mathrm{d}, \mathrm{g})$, North Germany $(\mathrm{b}, \mathrm{e}, \mathrm{h})$, South Germany $(\mathrm{c}, \mathrm{f}, \mathrm{i})$; Intensities given in $m m h^{-1}$. 

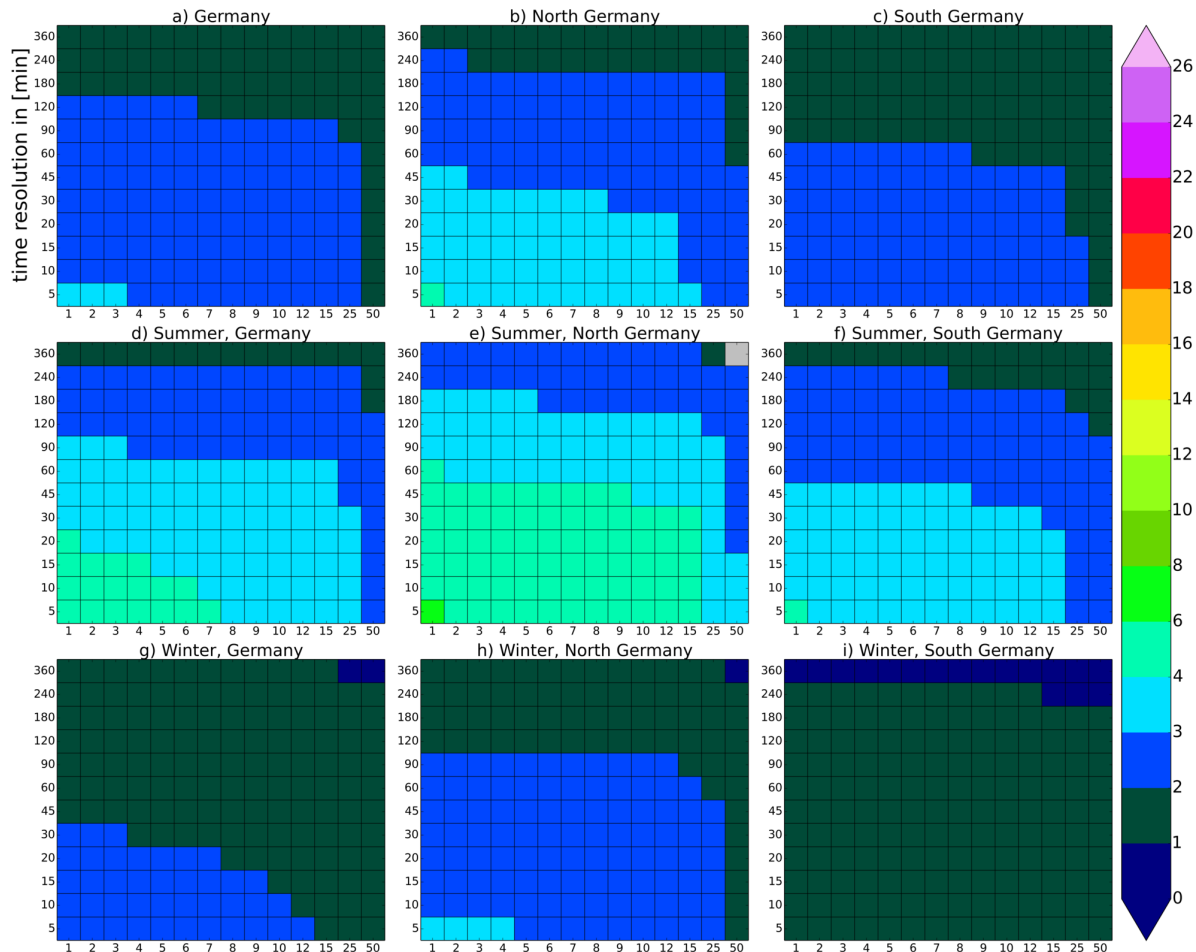

Winter, North Germany
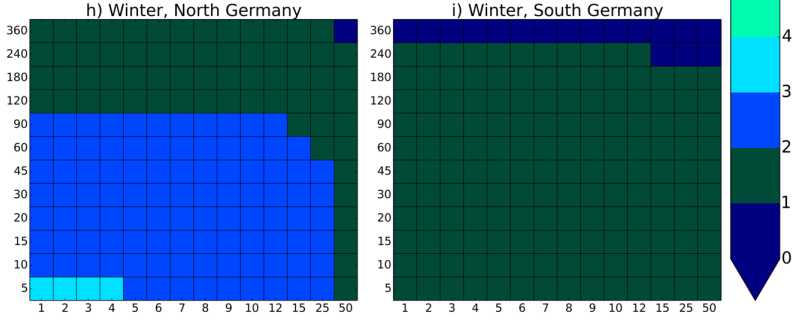

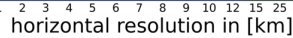

Figure 2: Stratiform extremes as function of resolution. Otherwise similar to Fig. 1. 

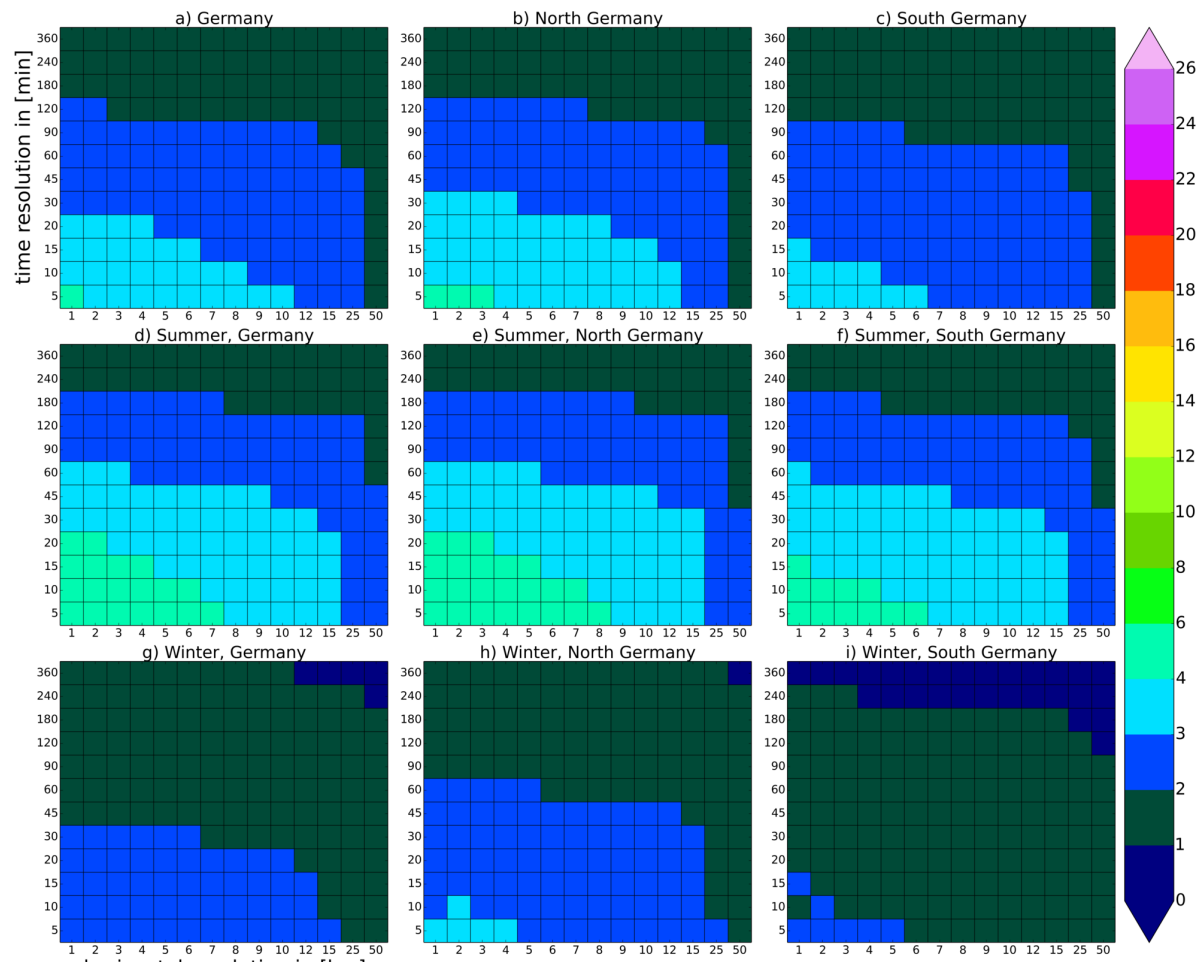

horizontal resolution in $[\mathrm{km}]$

Figure 3: Precipitation extremes as function of resolution. Otherwise similar to Fig. 1. 

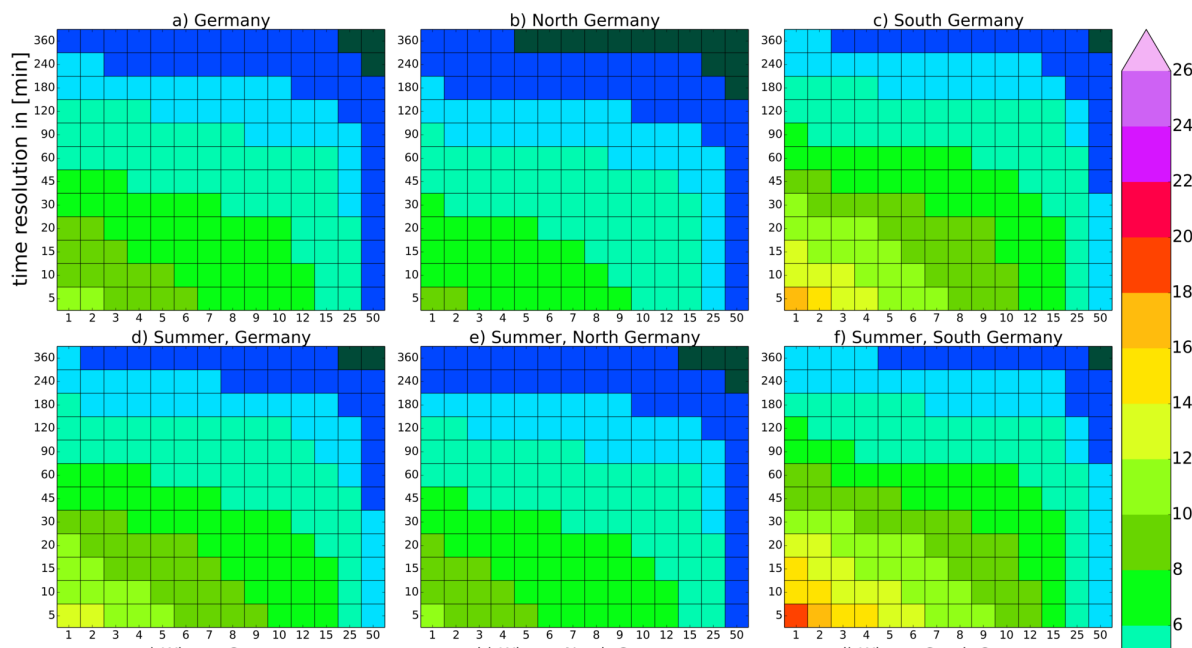

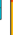
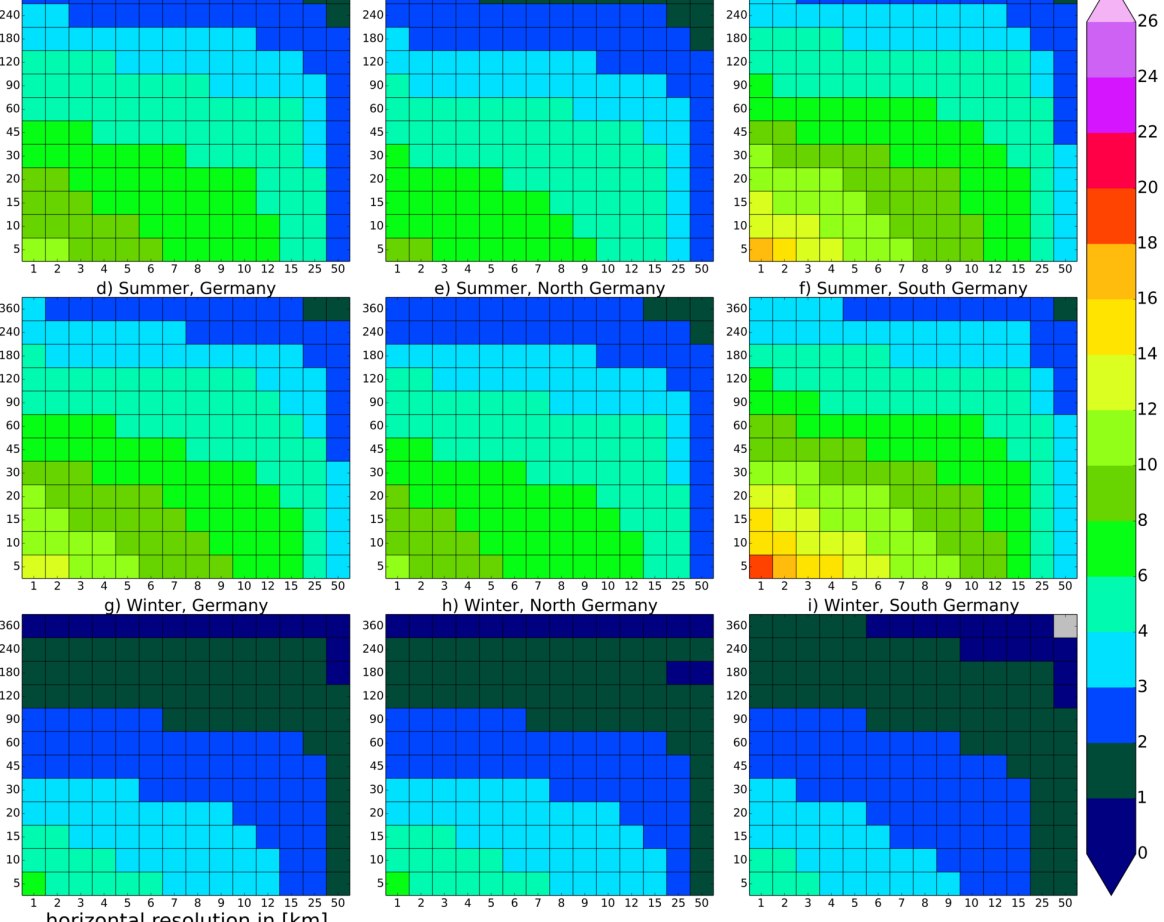

Figure 4: Convective extremes as function of resolution. The 98th percentile of convective precipitation intensities, Otherwise similar to Fig. 1. 

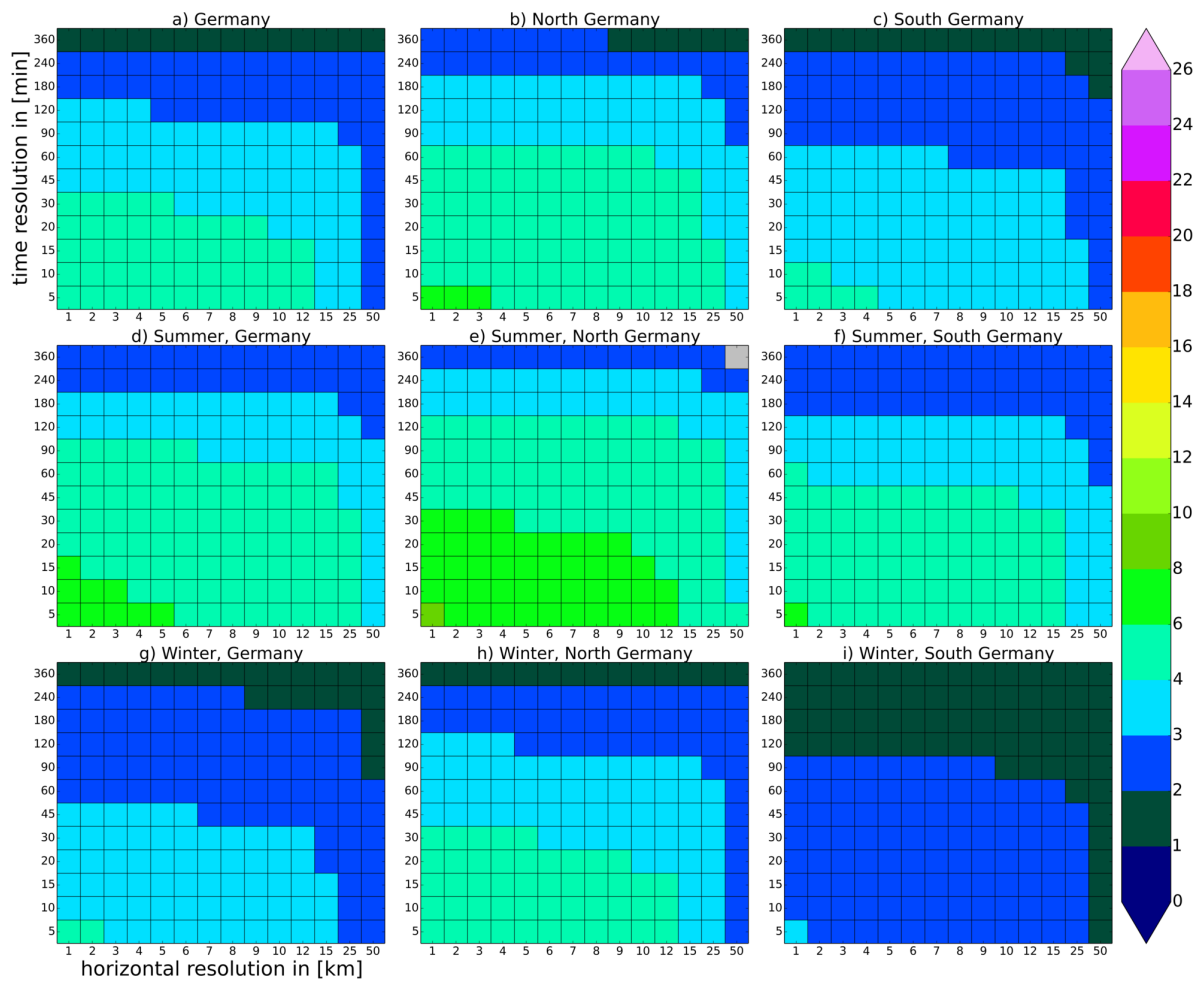

Figure 5: Stratiform extremes as function of resolution. The 98th percentile of stratiform precipitation intensities, Otherwise similar to Fig. 1. 

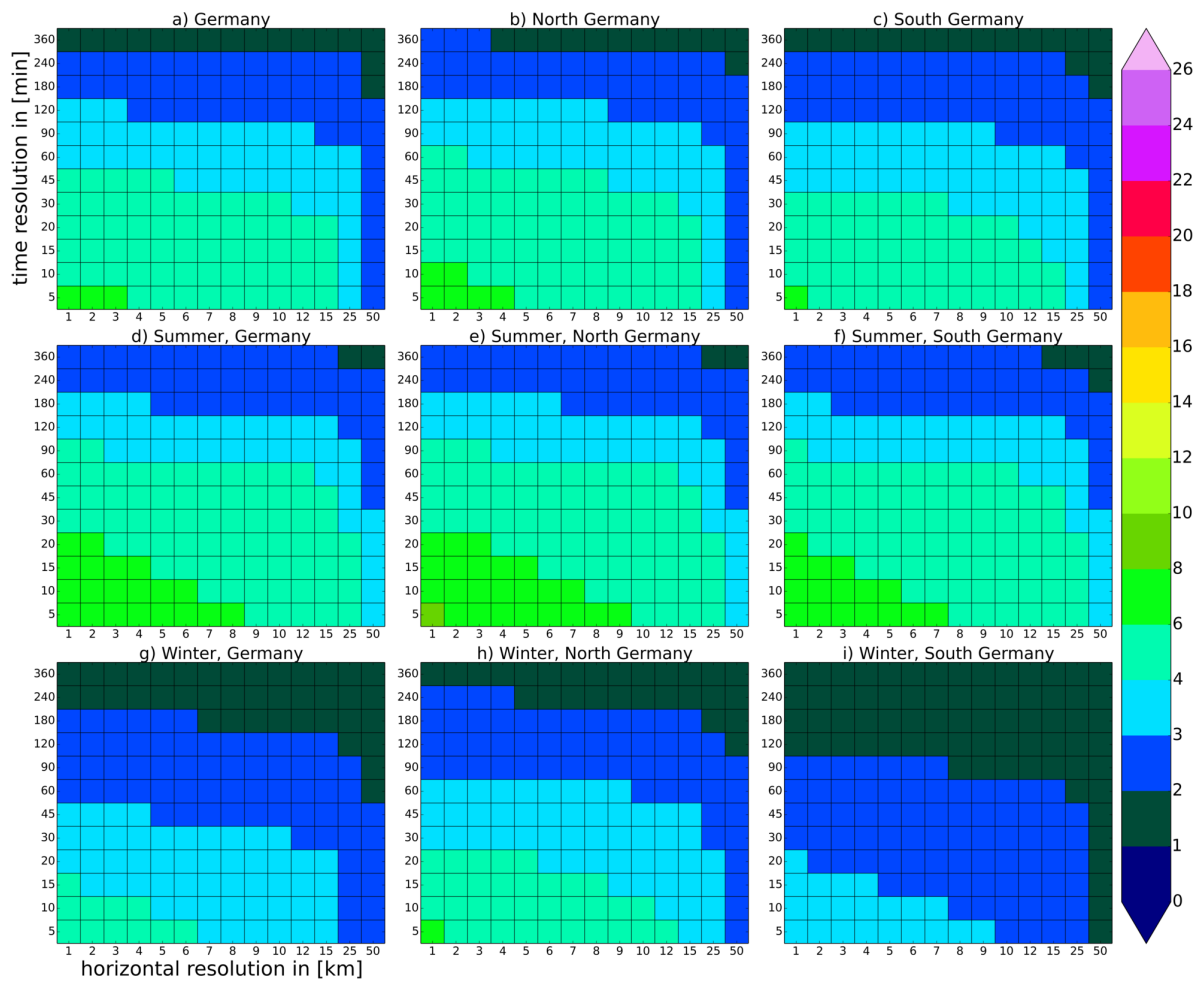

Figure 6: Precipitation extremes as function of resolution. The 98th percentile of precipitation intensities, Otherwise similar to Fig. 1. 

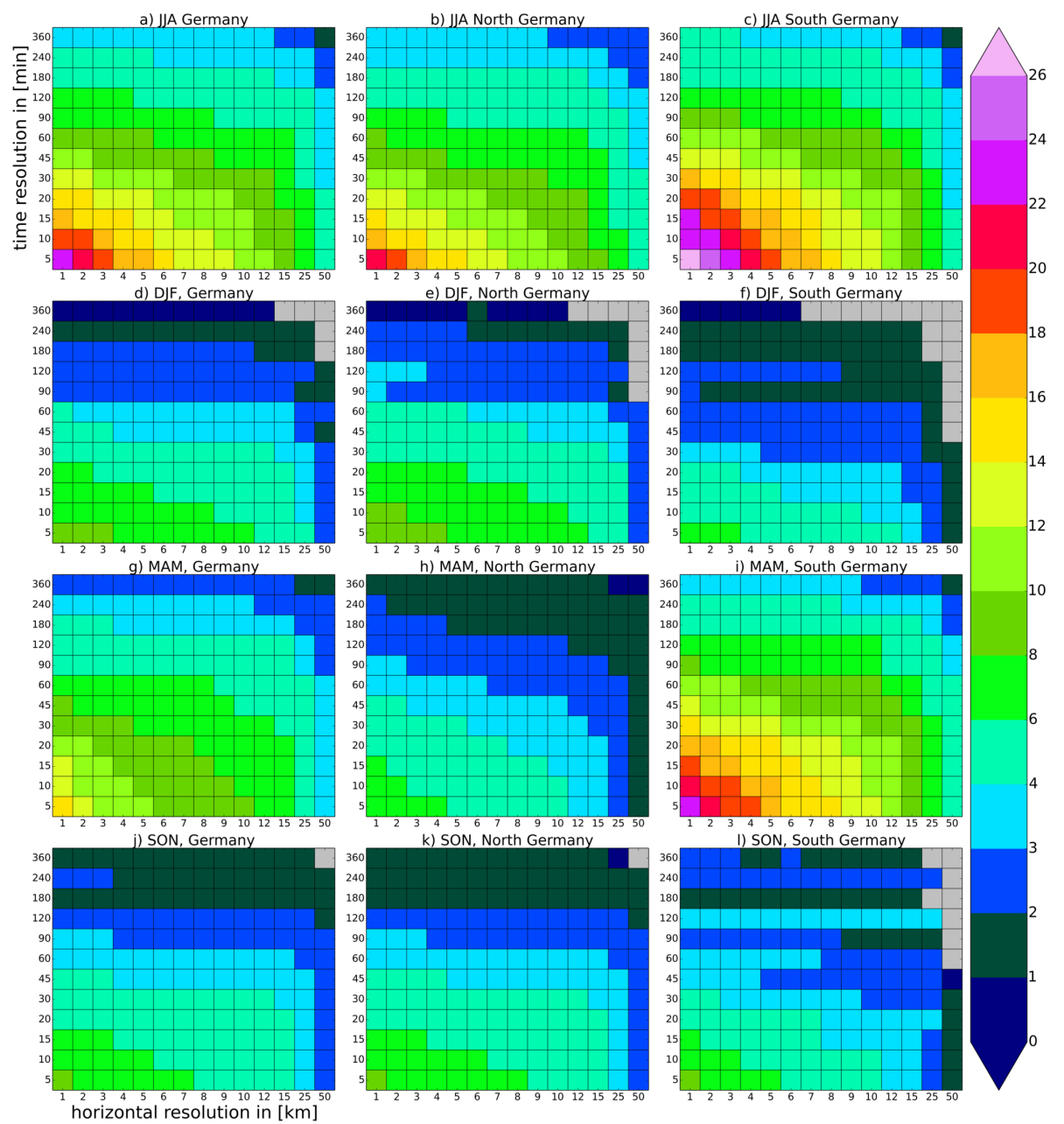

Figure 7: Convective extremes as function of resolution. The 99th percentile of convective precipitation intensities, aggregated over different parts of Germany for the years 2007-2008, on different horizontal (horizontal axis) and temporal (vertical axis) resolutions: Seasons: JJA (a,b,c), DJF (d,e,f), MAM $(\mathrm{g}, \mathrm{h}, \mathrm{i})$, and SON $(\mathrm{j}, \mathrm{k}, \mathrm{l})$. All of Germany $(\mathrm{a}, \mathrm{d}, \mathrm{g})$, North Germany (b,e,h), South Germany (c,f,i); Intensities given in $m m h^{-1}$. 

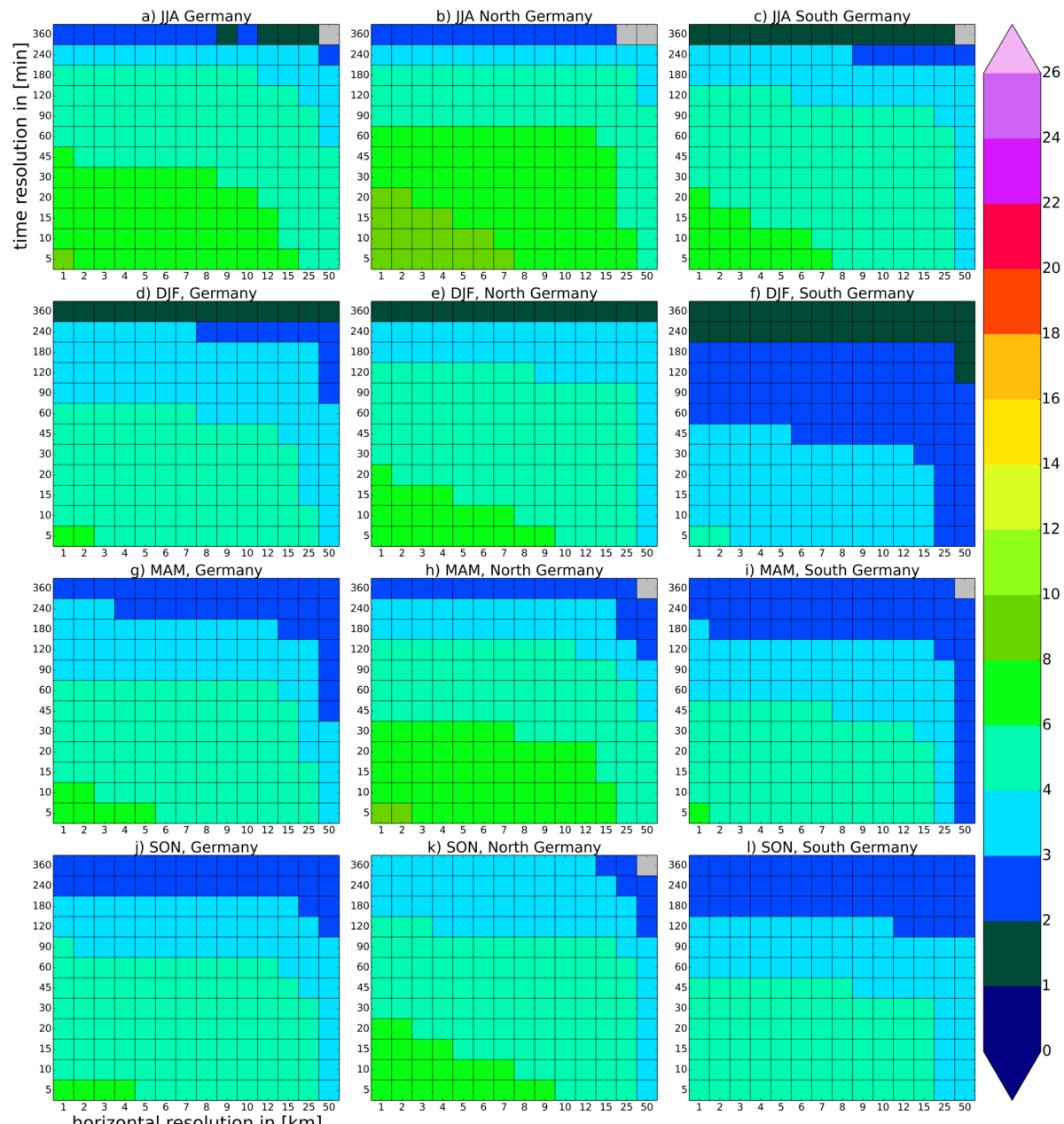

Figure 8: Stratiform extremes as function of resolution. Otherwise similar to Fig. 7. 

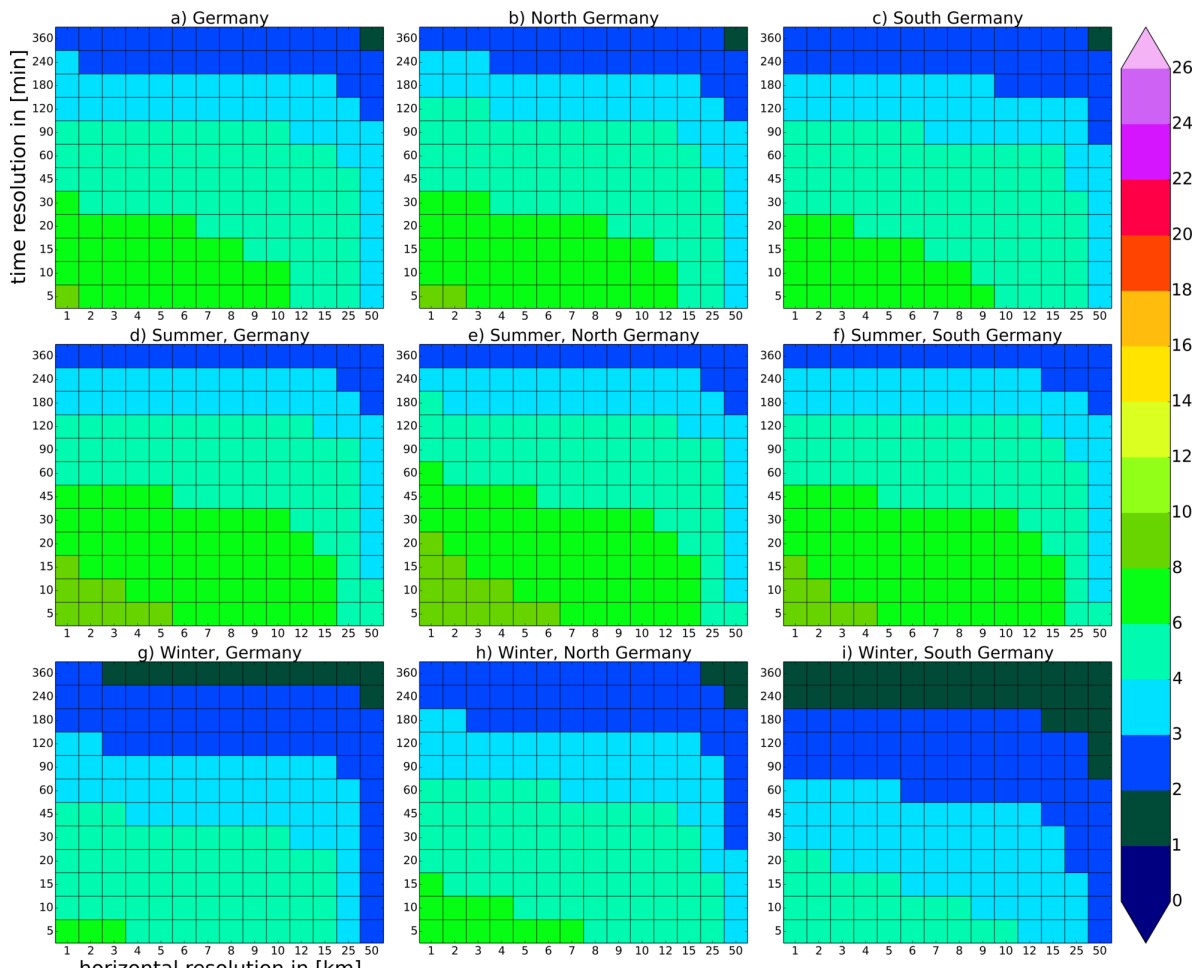

Figure 9: Precipitation extremes as function of resolution. The 99th percentile of precipitation intensities. Otherwise similar to Fig. 1. 

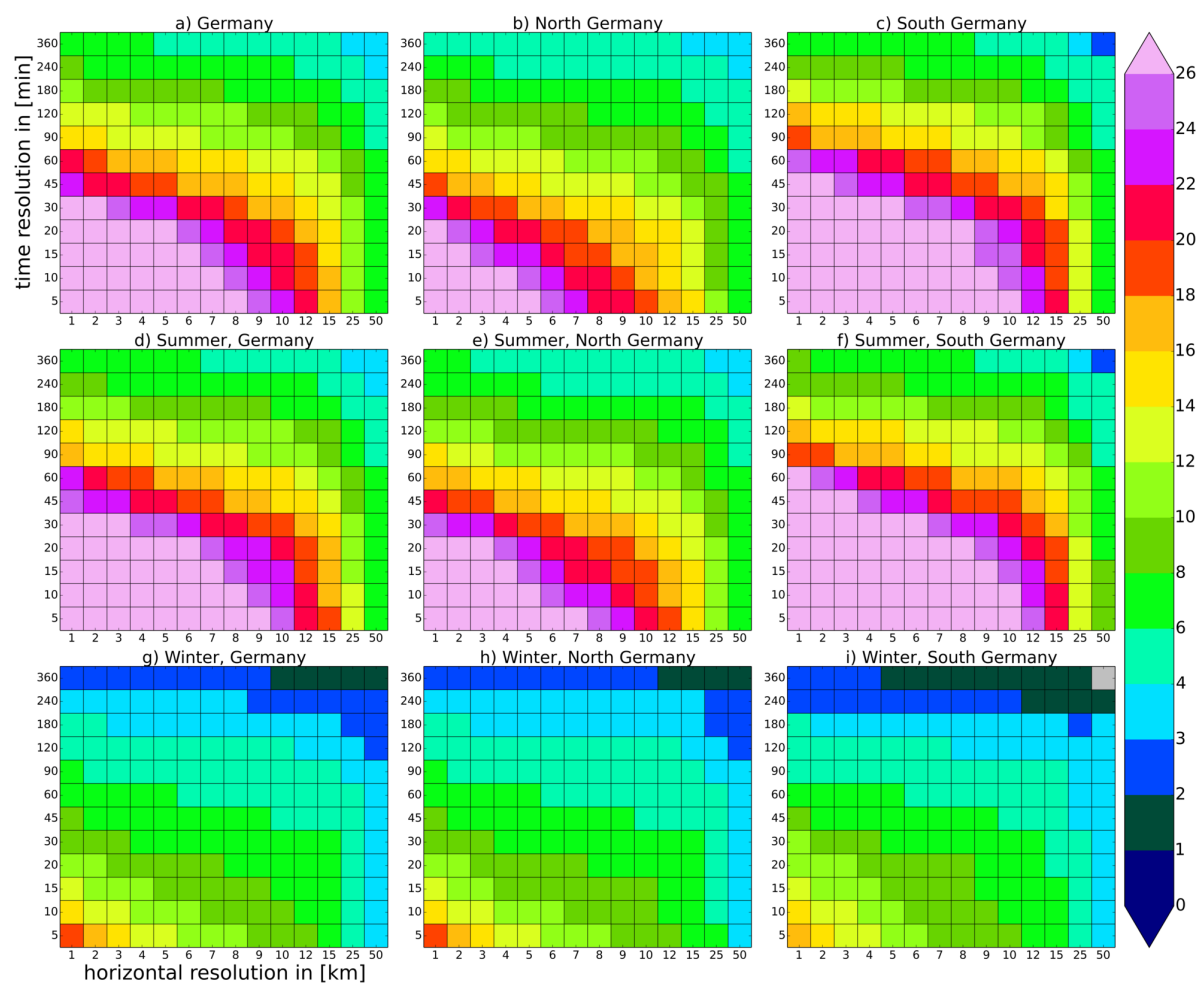

Figure 10: Convective extremes as function of resolution. The 99.9th percentile of convective precipitation intensities. Otherwise similar to Fig. 1. 

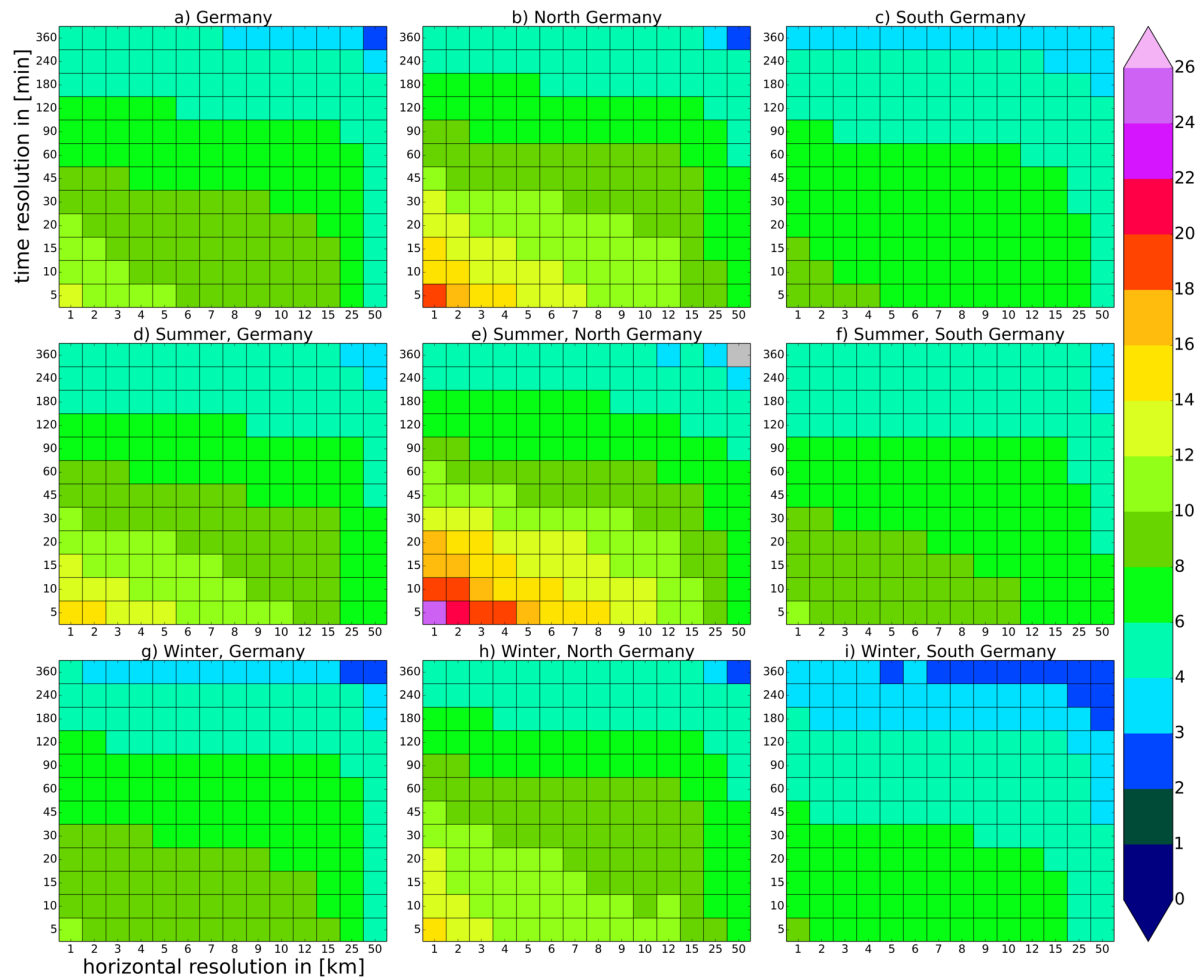

Figure 11: Stratiform extremes as function of resolution. The 99.9th percentile of stratiform precipitation intensities. Otherwise similar to Fig. 1. 

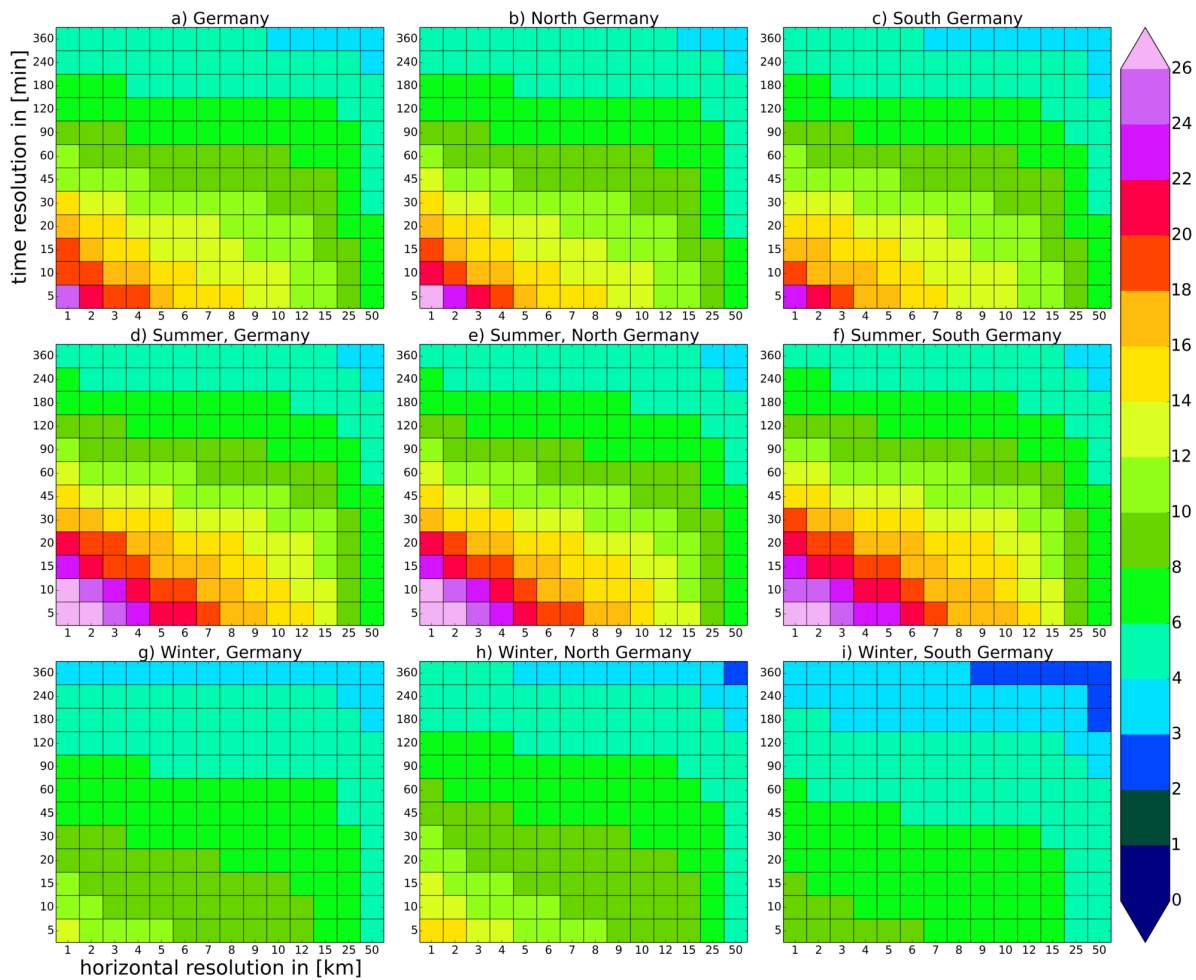

Figure 12: Precipitation extremes as function of resolution. The 99.9th percentile of precipitation intensities. Otherwise similar to Fig. 1. 


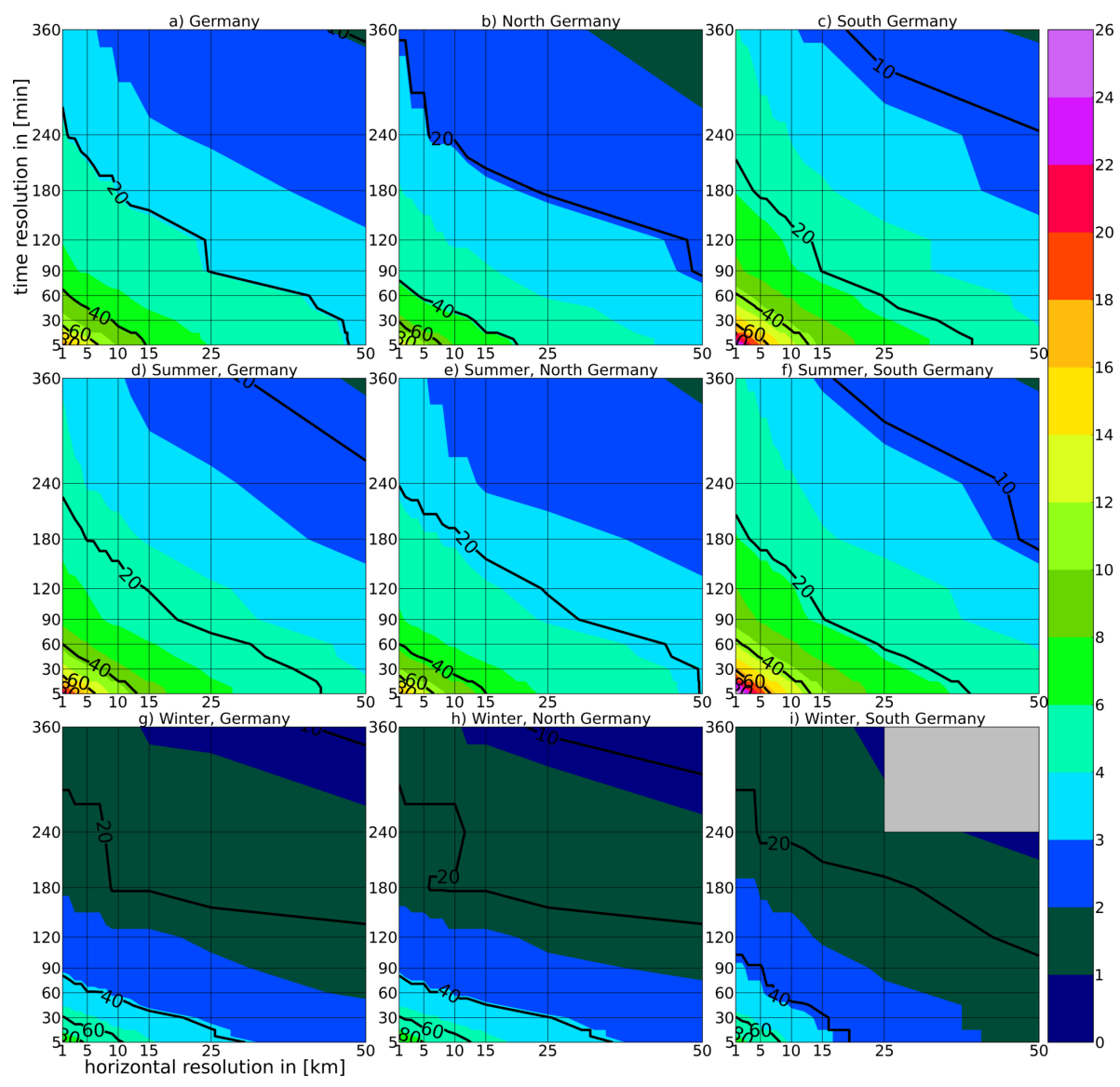

Figure 13: Convective extremes as function of resolution. The 99th percentile of convective precipitation intensities with a linear scaling at the $\mathrm{x}$ and y-axis. The contour lines indicate the intensity decrease in \%. Otherwise similar to Fig. 1. 


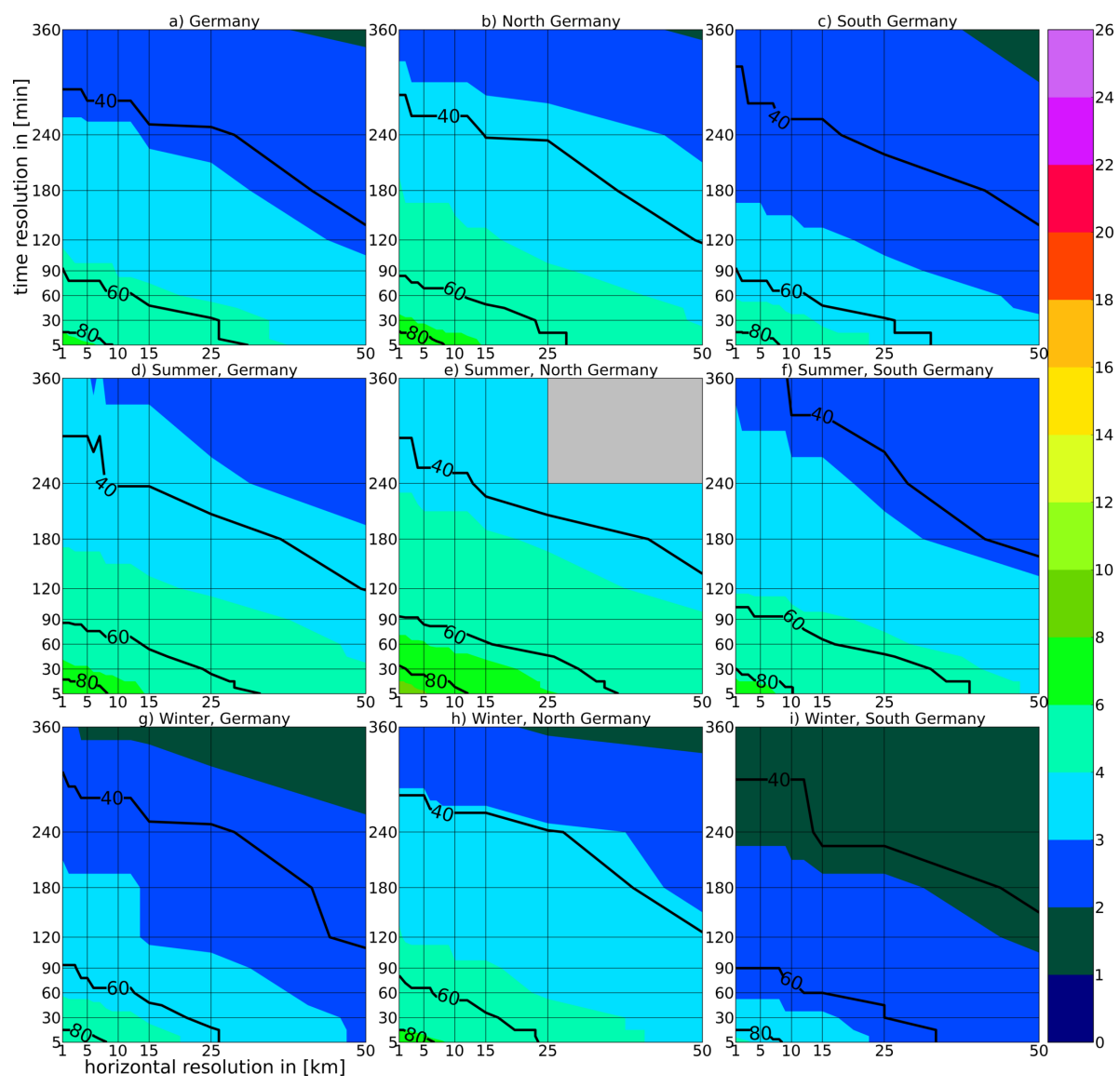

Figure 14: Stratiform extremes as function of resolution. The 99th percentile of stratiform precipitation intensities with a linear scaling at the $\mathrm{x}$ and y-axis. The contour lines indicate the intensity decrease in \%. Otherwise similar to Fig. 1. 

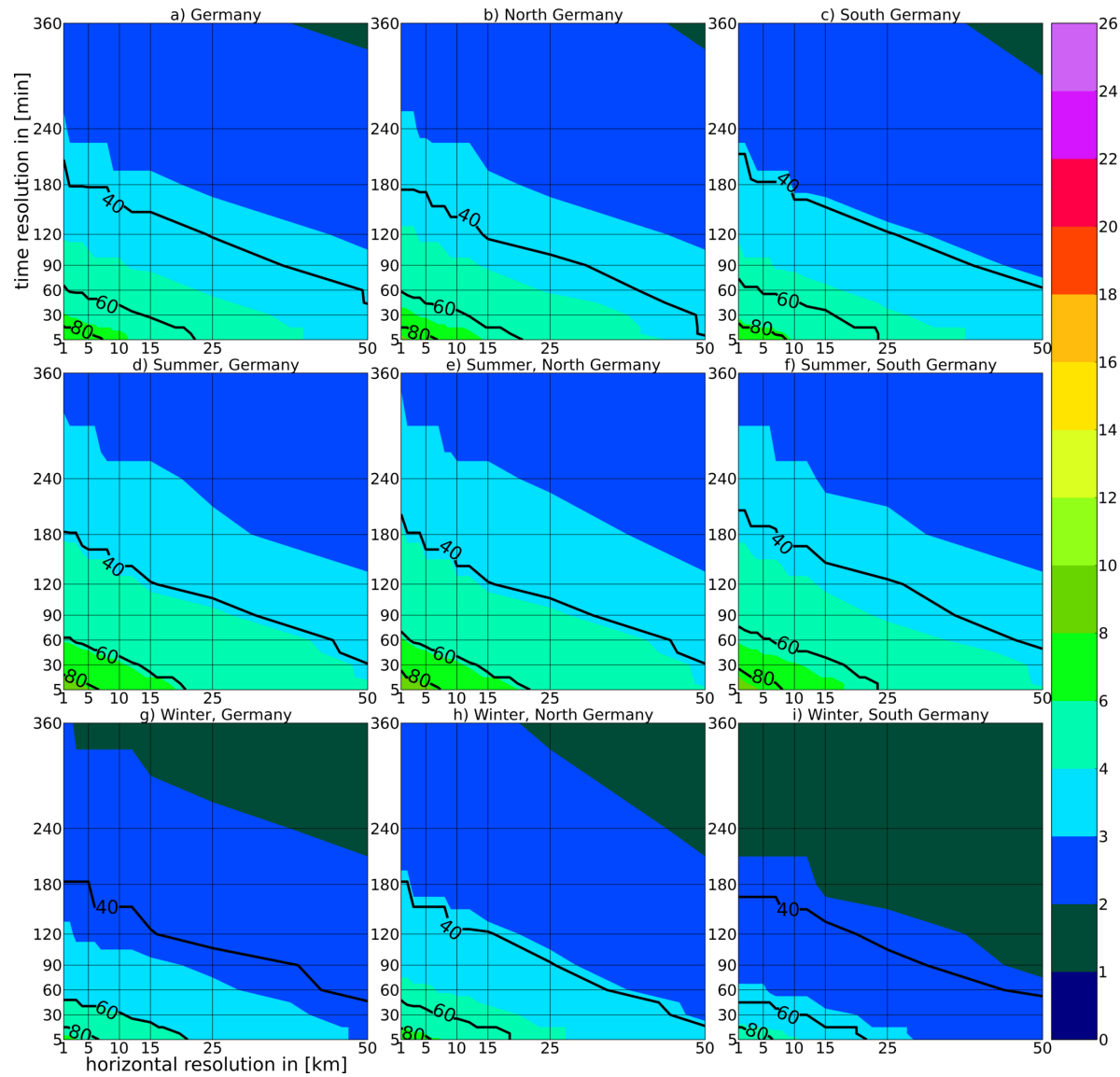

Figure 15: Precipitation extremes as function of resolution. The 99th percentile of precipitation intensities with a linear scaling at the $\mathrm{x}$ and $\mathrm{y}$-axis. Otherwise similar to Fig. 1. 

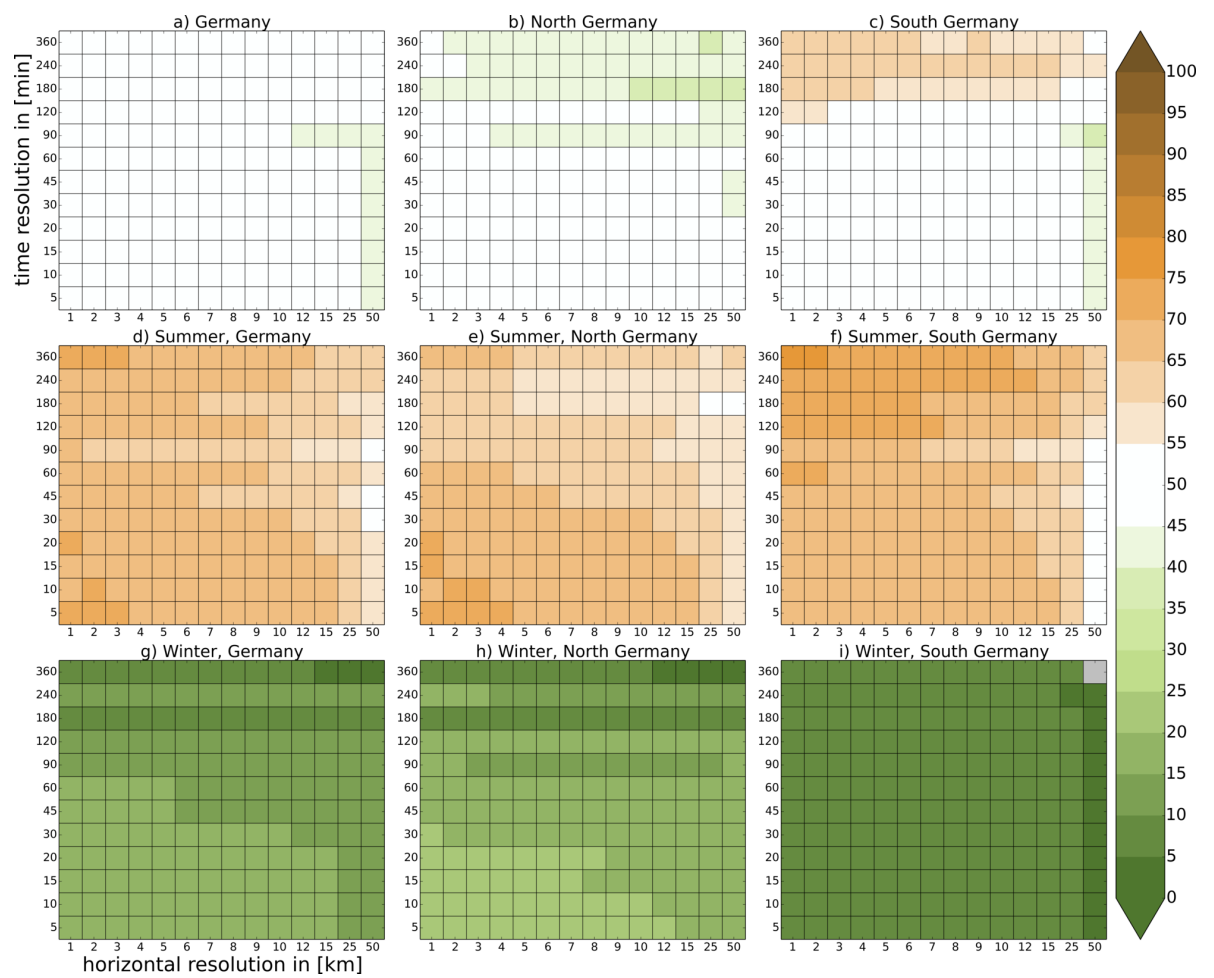

Figure 16: Convective dominance as function of resolution including dry periods. The ratio of the number of convective precipitation events with precipitation intensities larger or equal threshold intensity. Threshold intensity is defined as the 95th percentile of total precipitation intensities over the different parts of Germany for the years 2007-2008. Panels otherwise as in Fig. 1. 

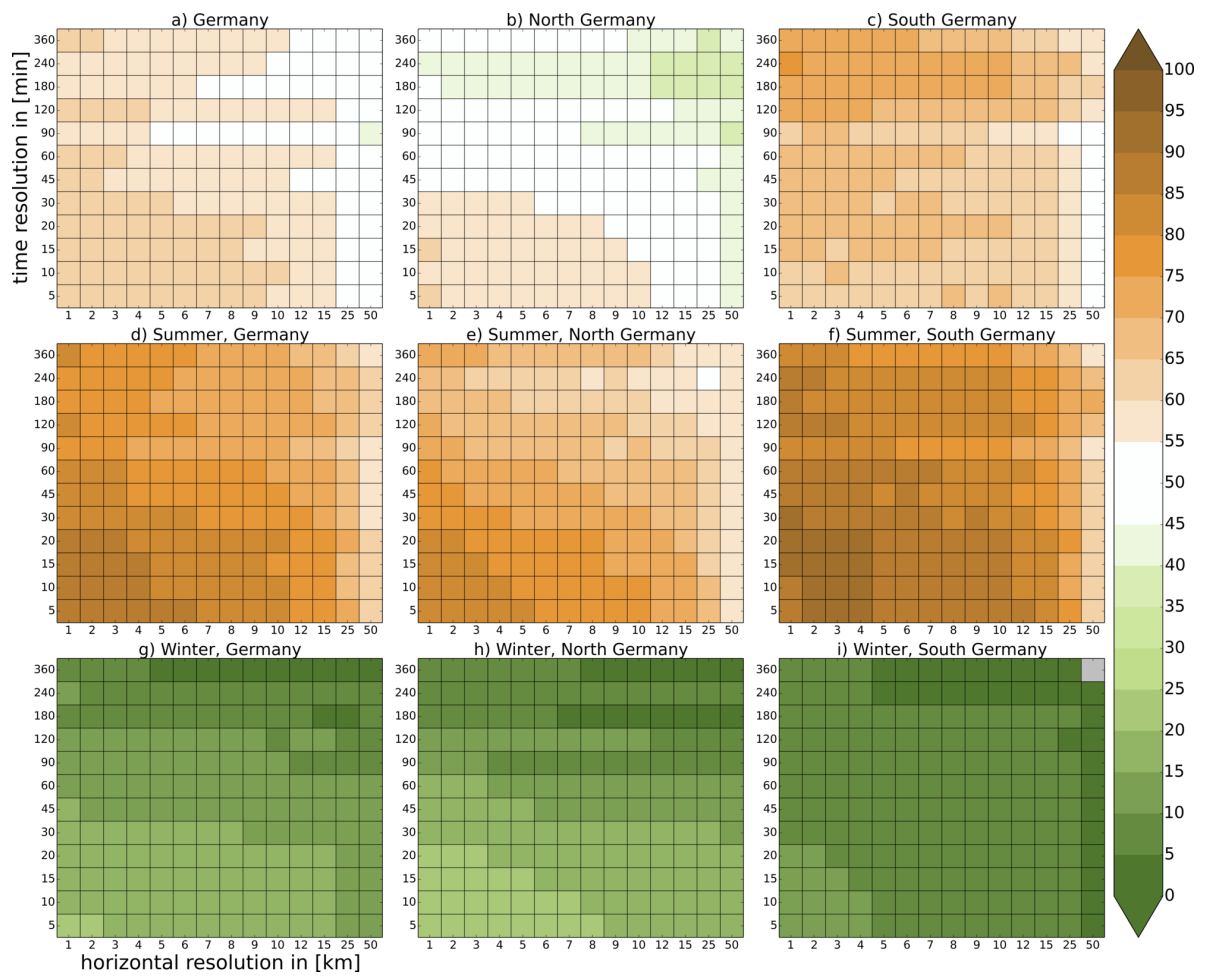

Figure 17: Convective dominance as function of resolution including dry periods. The ratio of the number of convective precipitation events with precipitation intensities larger or equal threshold intensity. Threshold intensity is defined as the 98th percentile of total precipitation intensities over the different parts of Germany for the years 2007-2008. Panels otherwise as in Fig. 1. 

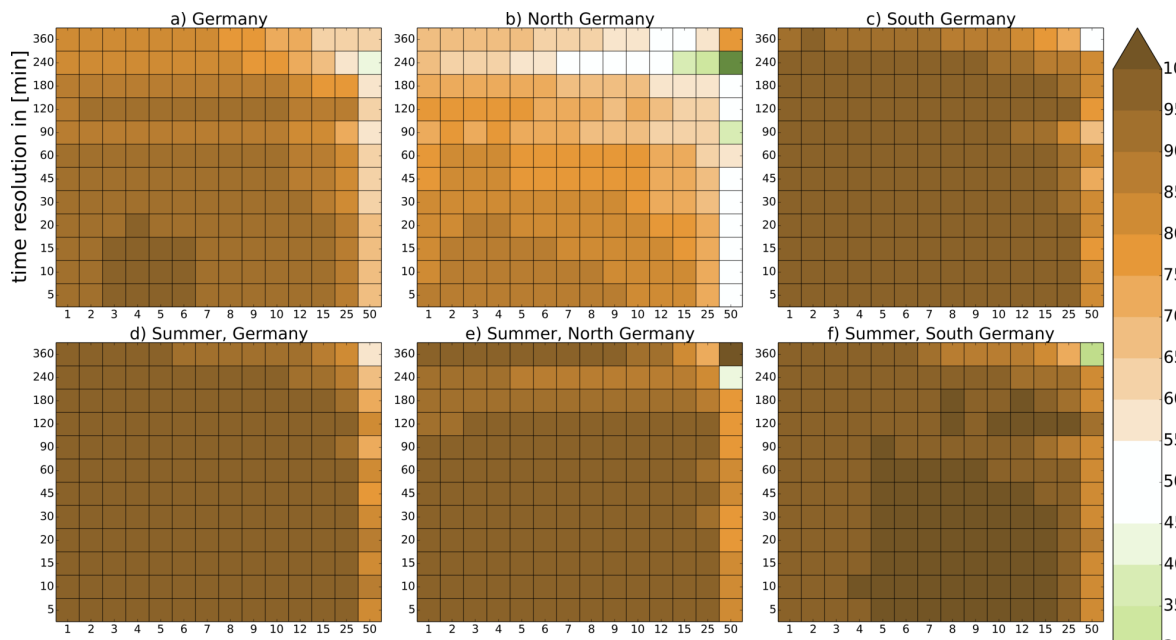

h) Winter North Germany
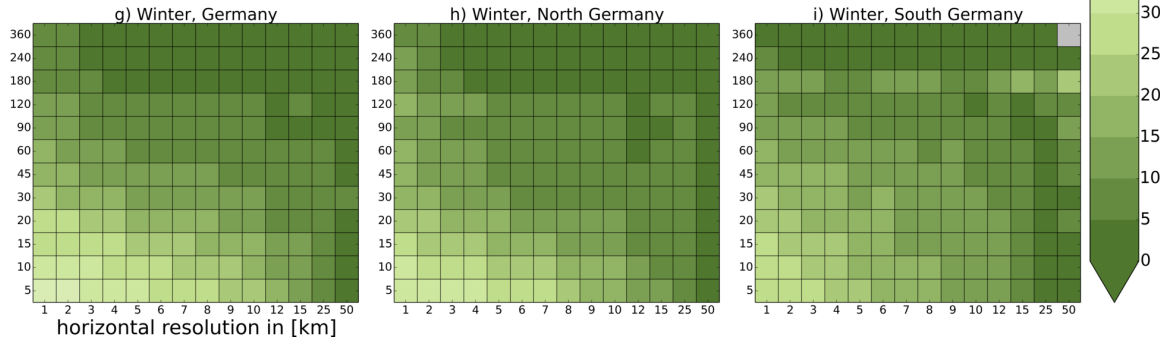

Figure 18: Convective dominance as function of resolution including dry periods. The ratio of the number of convective precipitation events with precipitation intensities larger or equal threshold intensity. Threshold intensity is defined as the 99.9th percentile of total precipitation intensities over the different parts of Germany for the years 2007-2008. Panels otherwise as in Fig. 1. 

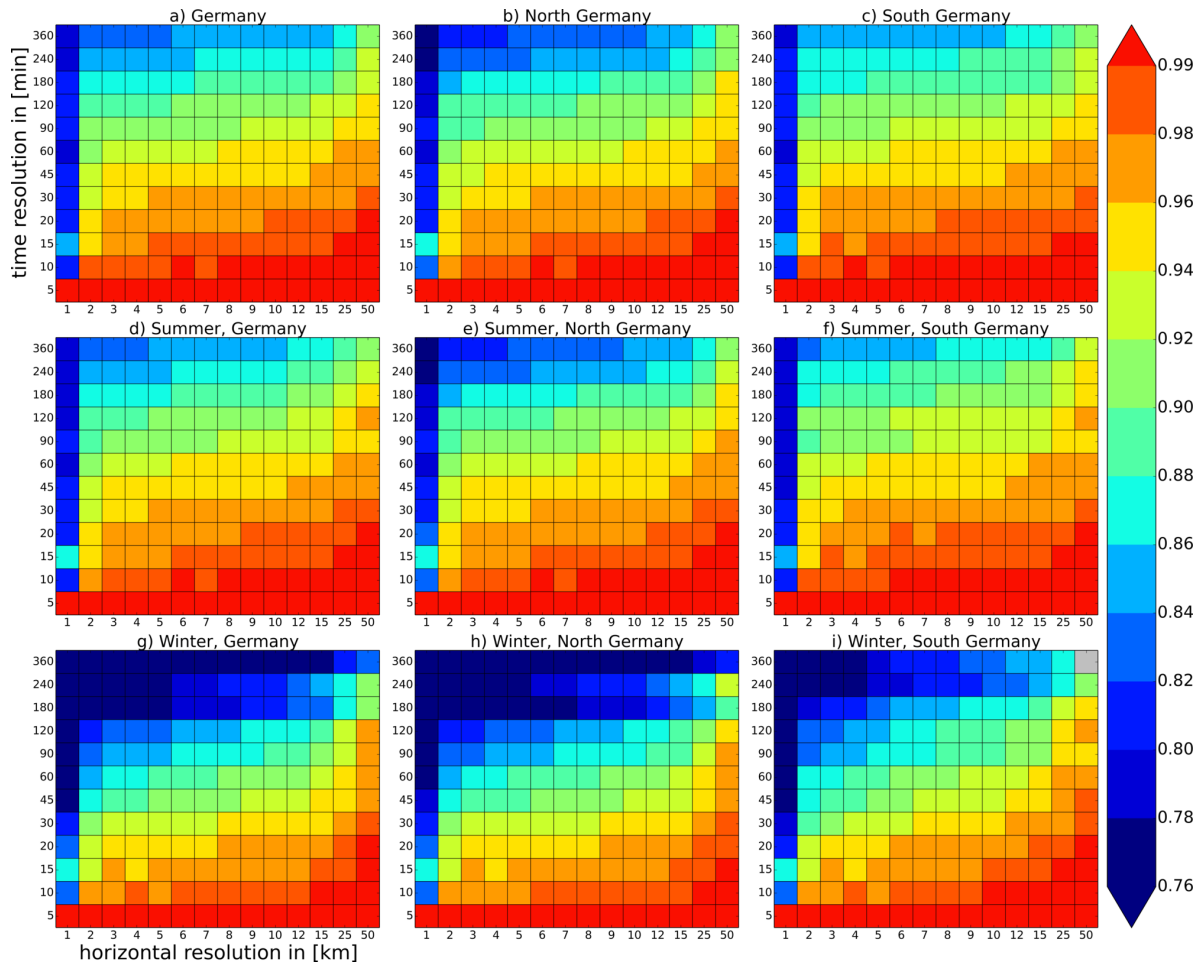

Figure 19: PDF overlap for convective precipitation intensity. PDF overlap of each horizontal resolution between every temporal resolution and the 5 minute data. Panels otherwise as in Fig. 1. 

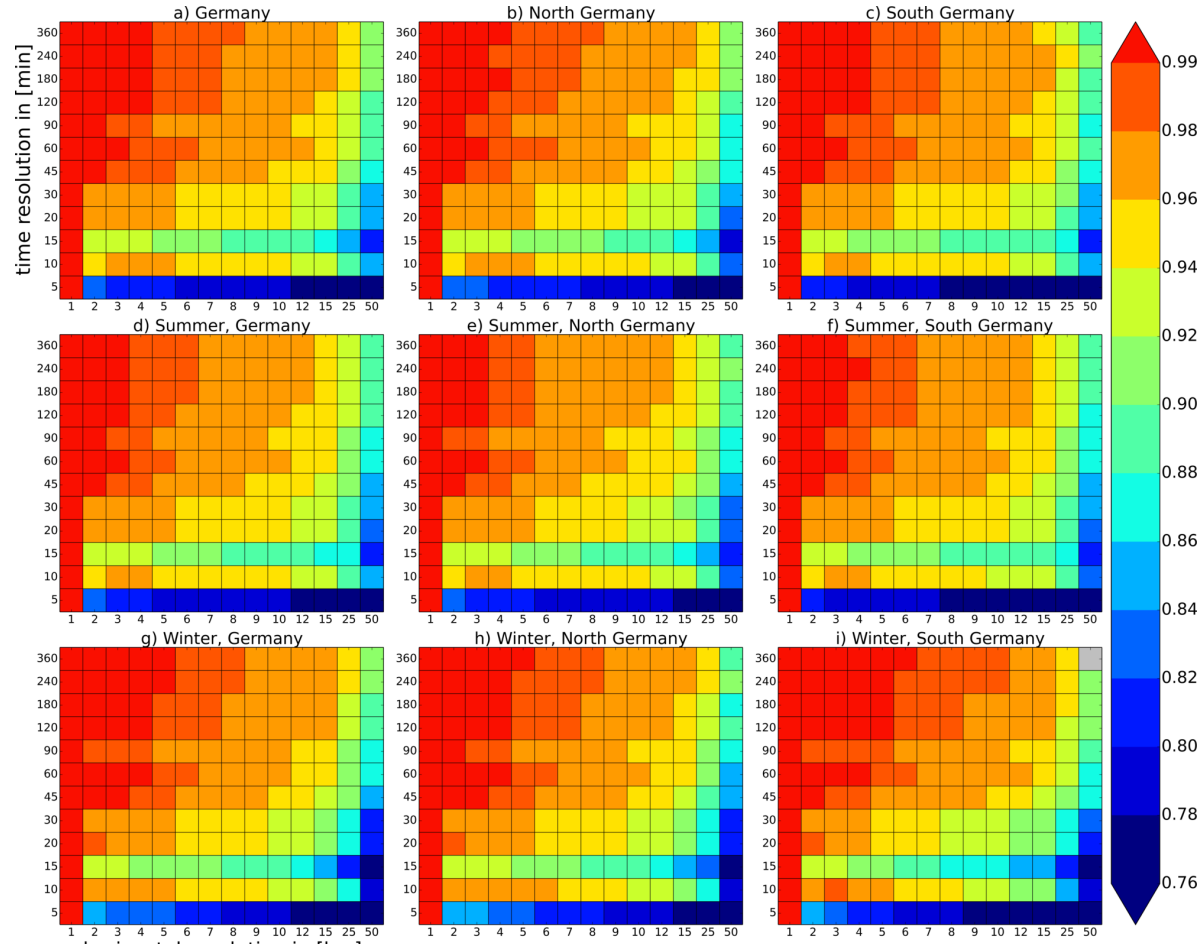

horizontal resolution in $[\mathrm{km}]$

Figure 20: PDF overlap for convective precipitation intensity. PDF overlap of each temporal resolution between every horizontal resolution and the $1 \mathrm{~km}$ data. Panels otherwise as in Fig. 1. 

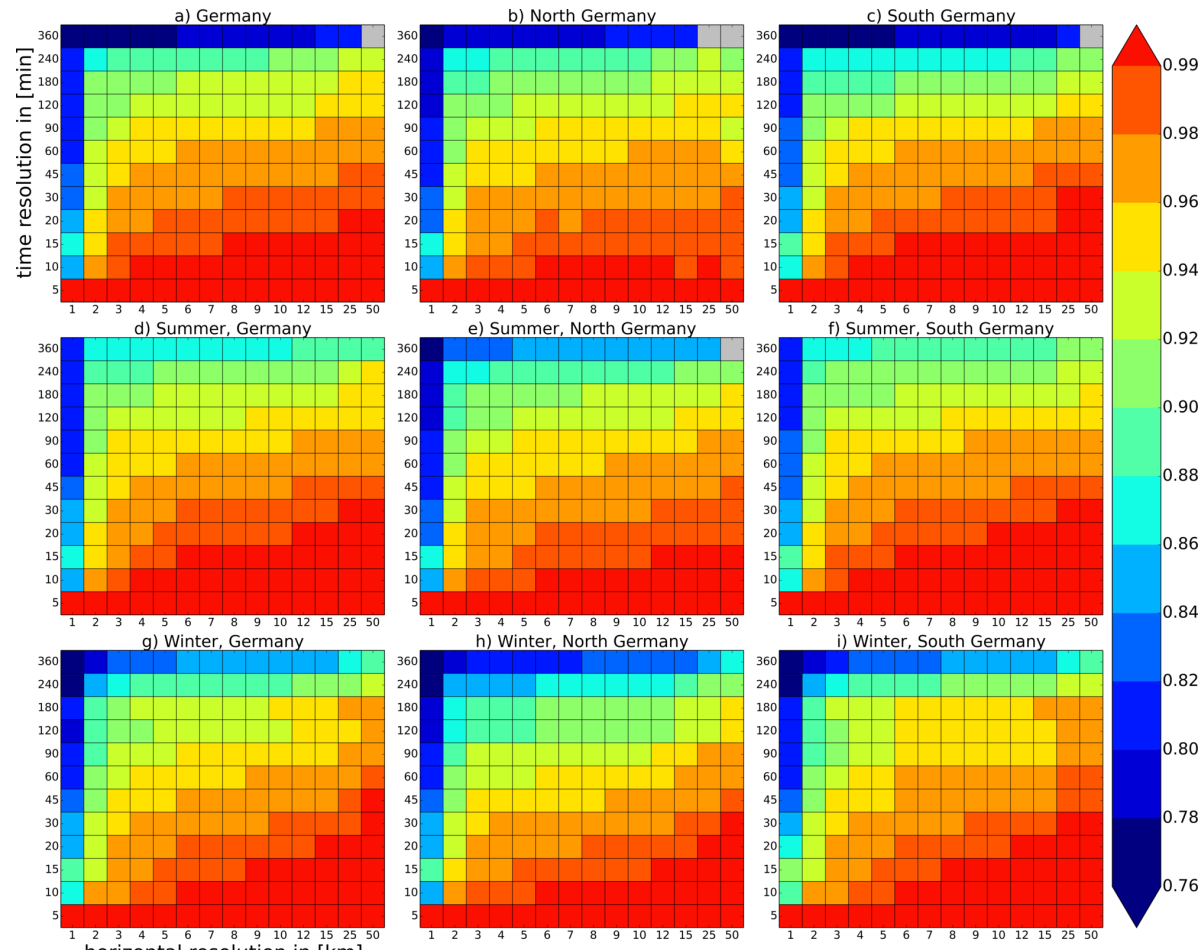

Figure 21: PDF overlap for stratiform precipitation intensity. PDF overlap of each horizontal resolution between every temporal resolution and the 5 minute data. Panels otherwise as in Fig. 1. 

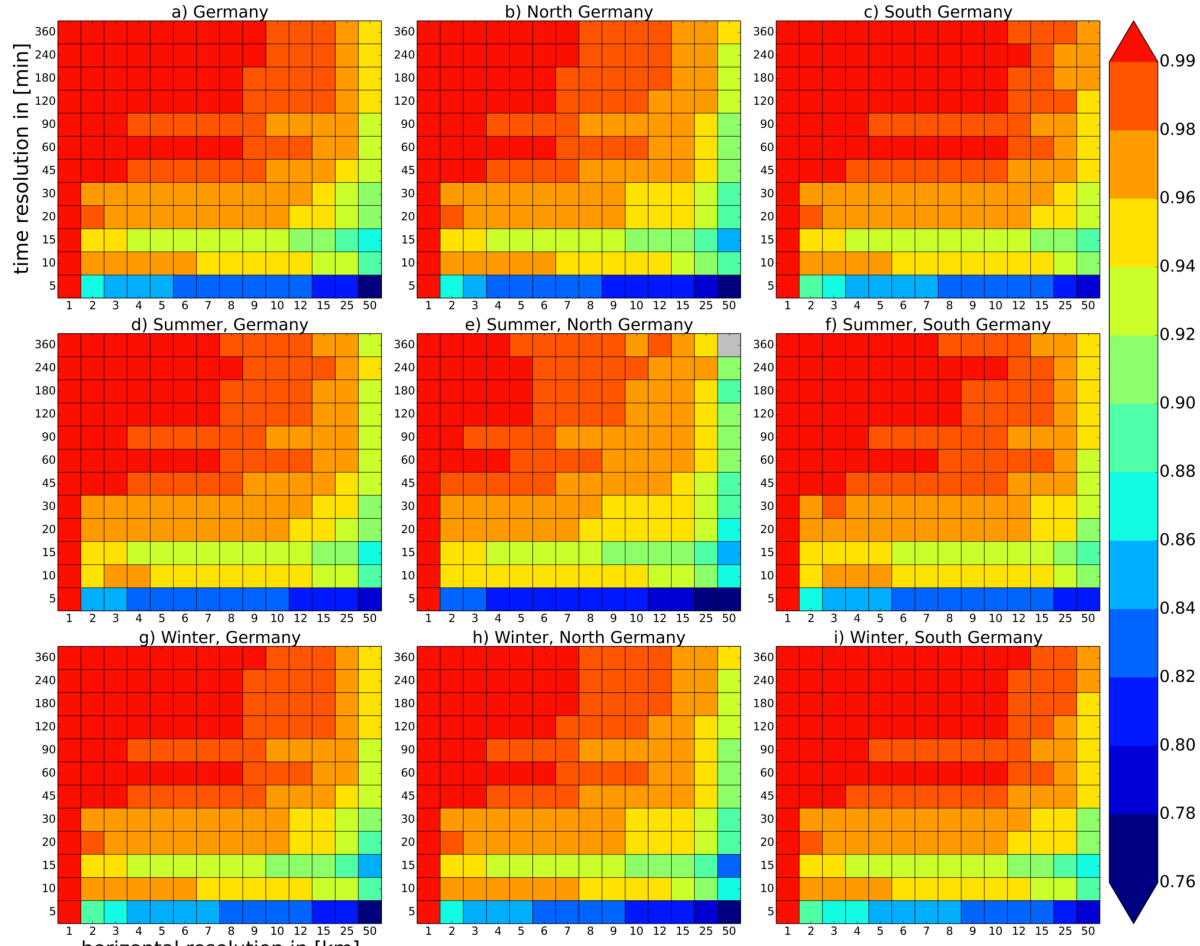

Figure 22: PDF overlap for stratiform precipitation intensity. PDF overlap of each temporal resolution between every horizontal resolution and the $1 \mathrm{~km}$ data. Panels otherwise as in Fig. 1. 
a)

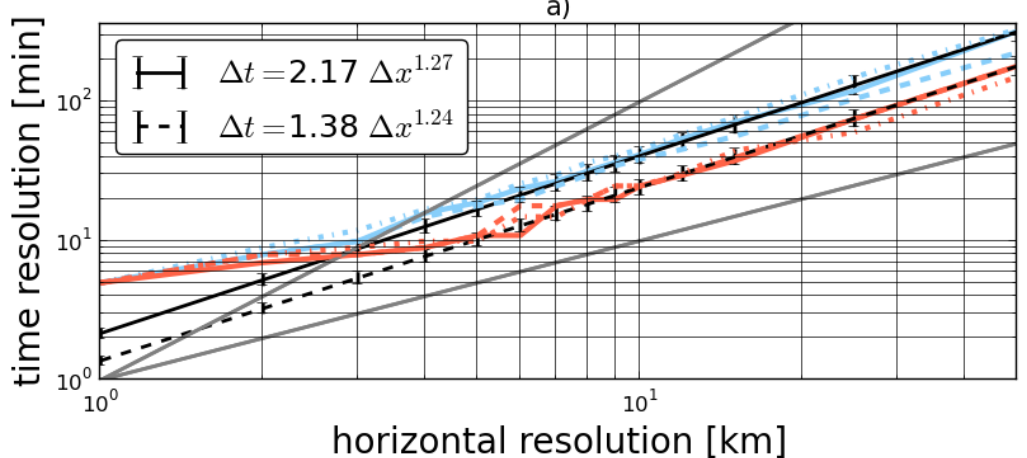

b)

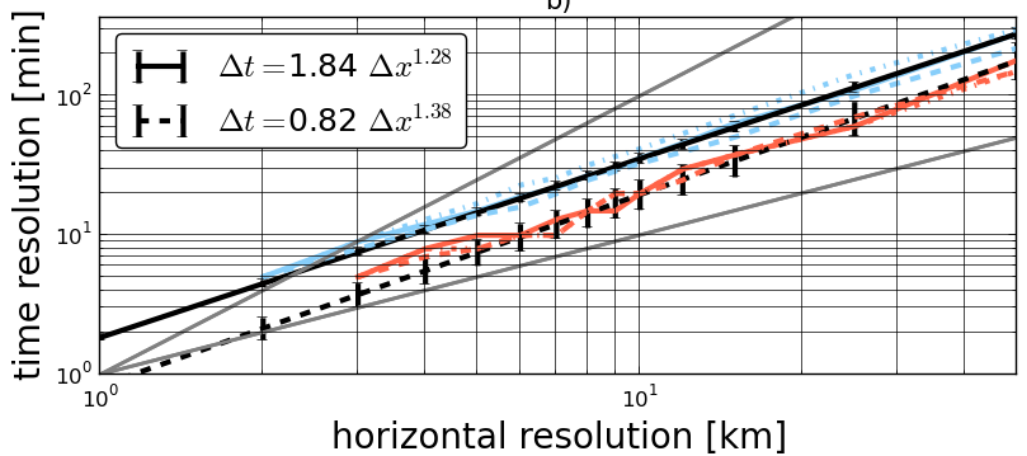

c)

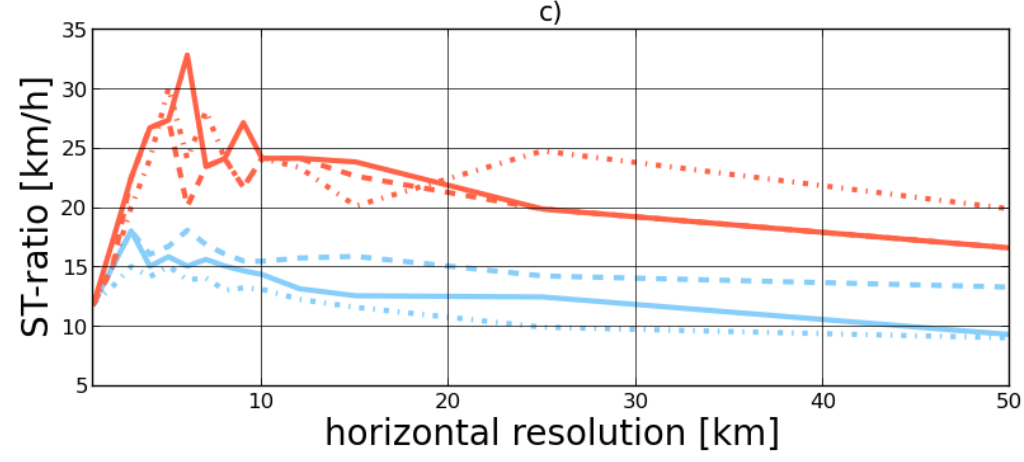

\begin{tabular}{|llll|}
$-\ldots$ & Convective & - & Stratiform \\
$\ldots$ & Convective North & - - & Stratiform North \\
\hline & Convective South & $\ldots$ & Stratiform South \\
\hline
\end{tabular}

Figure 23: Consistent spatial and temporal resolutions. $\Delta t$ derived using Eq. 5 for different values of $\Delta x$ for convective (blue) and stratiform (red) precipitation extremes at the 99th percentile for entire germany, north germany and south germany. Black lines are least square fit of $\Delta t=a \times \Delta x^{b}$ with the fitting parameters $a$ and $b$ for entire germany. Errorbars indicate the standard deviation of parameter estimates. Gray lines show $\Delta t \sim \Delta x$ and $\Delta t \sim \Delta x^{2}$, respectively. a, Initial resolutions $\Delta t_{0}=5 \mathrm{~min}, \Delta x_{0}=1 \mathrm{~km} . \mathbf{b}, \Delta t_{0}=5 \mathrm{~min}$, and aggregated spatial resolutions $\Delta x_{0}=2 \mathrm{~km}$ (convective) and $\Delta x_{0}=3 \mathrm{~km}$ (stratiform). c, ST-ratio (Eq. 7) for both precipitation types for different parts of Germany over the entire year. 